Contents List available at RAZI Publishing

Environment \& Ecosystem Science (EES)

Journal Homepage: http://www.razipublishing.com/journals/environment-and-ecosystem

https://doi.org/10.26480/ees.02.2017.13.15

\title{
DETERMINING THE SENSITIVE CONSERVATIVE SITE IN KOLAH GHAZI NATIONAL PARK, IRAN, IN ORDER TO MANAGEMENT WILDLIFE BY USING GIS SOFTWARE
}

\author{
Alireza Radan1, ${ }^{\star}$ Milad Latifi1, Minoo Moshtaghie2, Mozhgan Ahmadi3, Maryam Omidi3 \\ ${ }^{1}$ Young Researchers and Elite Club, Isfahan (Khorasgan) Branch, Islamic Azad University, Isfahan, Iran. \\ ${ }^{2}$ Isfahan (Khorasgan) Branch, Islamic Azad University, Isfahan, Iran \\ ${ }^{3}$ Esfahan provincial office of the Department of the environment, Esfahan, Iran \\ *Corresponding author email: milad.latifi6@gmail.com
}

This is an open access article distributed under the Creative Commons Attribution License, which permits unrestricted use, distribution, and reproduction in any medium, provided the original work is properly cited.

\section{ARTICLE DETAILS}

\section{Article History:}

Received 5 July 2017

Accepted 7 October 2017

Available online 4 November 2017

Keywords:

Species Riches, Kolah Ghazi

National Park, strategic management, Sensitive

Conservative

\section{ABSTRACT}

One of the basic keys in the conservation and management principle of protected region especially national parks is identifying the ecological resources of the region. Undoubtedly in each ecosystem, there are regions which are more significant in terms of riches species and the presence of valuable and important species (conservative sensitive site) has favorable conditions than the other regions, these regions are significant in terms of conservation strategies and ecotourism management. Therefore, identifying this sensitive conservative site could have new evaluation in the management of conservative regions. The aim of this research was presenting solutions for biodiversity strategic managements, by considering sensitive conservative site in Kolah Ghazi National Park. During one-year regular monitoring of the Kolah Ghazi National Park, in Isfahan, diversity and abundance of fauna and flora of the region in terms of species richness with their exact geographical position were recorded by direct observation. Available documentary data and regional profiles were used to complete data. For evaluating data random pallet $\mathrm{m} 2400$ methods and also the distance from the nearest neighbor were used. By overlaying ecological maps by using GIS software, a conservation map was prepared in which three conservation levels (high, medium and low protection) were considered for the region. The highest density of species is on the spot which is marked on the map as high conservation. In the following, suitable management strategy for each season, according to three categories of conservation of the lo, medium and high will be provided.

\section{INTRODUCTION}

Now a days, purposeful studies and analyses of different habitats conditions are considered as one of the principles of management and conservation of wildlife species. Desirable habitat will have remarkable impact on survival and reproduction of the species and is also important to management and conservation of the wild life [1] One of the fundamental keys in the principles of conservation and management of protected areas especially national parks is to identify the ecological and physical resources of the region. Now a day, maintaining biodiversity is one of the fundamental objectives of environmental managements. Species diversity has been consistently decreasing in all over the world and has exposed the populations to serious threats [2].

Biodiversity is a fundamental concept in ecology and in plant and animal management. It also plays an important role in ecosystems evaluation. Analysis and diversity of these communities improve human awareness and is a way to achieve sustainable management. Due to the presence of valuable mammalian fauna Kolah Ghazi National Park requires comprehensive conservation. Due to the existence of historical places, high population of wild goats and deer, multiple spring, have provided a relatively good condition for attracting tourist and mountaineers. If the biodiversity protection of the area is well protected, it will increase specious richness in the region, which will lead to more tourists. Management and conservative biodiversity requires identification of species to maintain stability in ecosystem [3].

In each countries', s genetic domain mammals are among the most important species and the presence and richness, each of them, in view of the specific species richness in each region, can determine the specific conservation pattern for each region. The presence of artiodactyl animals such as wild goats in Kolah Ghazi region requires researchers to determine a strategic plan for protection of the region.

Birds are considered as a national wealth of our country, unfortunately due to the lack of supervision in their habitats a large number of them because of destruction of ecosystem have been greatly reduced [3]. The excessive hunting and degradation of the habits has threated biodiversity of the birds. To manage a habitat, region with a strong wildlife are at the top of the list for this reason this region needs more protection, because these regions represent the biodiversity of the region and are a part of sensitive regional area requires more managements [4].

What is now a day being developed as a protected region network under the management of Environmental protection agency (also developed day by day) is a conscious response to protect specious in the left natural habitats against threats and natural destruction [5]. There for the purpose of proper management and principle of habit and ecosystem a method of ranking and valuation has been investigated in these regions.

The purpose of this study is to provide strategic management strategies for biodiversity with consideration of sensitive conservative site in the Kolah Ghazi National Park.

\section{METHODOLOGY}

Kolah Ghazi National Nark located in the southeast of Isfahan, Iran, and Isfahan-Shiraz road passes through northwest side. The area of the region is 47,262 hectares. The climate is warm and dry. Due to its special conditions, Kolah Ghazi National Park has long been wild life habitats and has a long history [6]. Kolah Ghazi Mountain is a part of Maahdasht mountain range. The highest pick of this mountain reaches 2534 meters. The National Park vegetation, in addition of herbaceous cover, has tree and shrub species.

This study was conducted in a one-year period, during which population estimation methods (transect), profiles, photography, previous information, frequency and diversity of mammals and birds in each region were determined [7]. Due to the high conservative values of the birds and mammals especially the wild goats, the distribution maps were prepared by using GIS software (figure 3 and 4). By integrating these two maps areas of overlapping are sensitive areas and more stringent protection is 
required, and the point that has less overlapping, included in the lowest protection categories (figure 5). Inverse distance weighing (IDW) method was used to zone the dispersion of the birds and mammals. In order to set conservational priorities, topographic, plant life and birds and mammals' dispersion maps were overlaid and the region was divided into three conservation levels (high, medium and low) by using Spatial analyst tool in ARCGIS software [8-11]

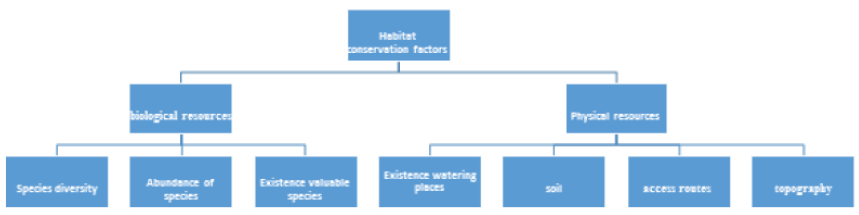

Figure 1: Habitat conservation factors

In addition of factors mentioned in figure 1 , other factors such as economic and resources are important, but, among all, biological conservative factors or frequency and diversity of wildlife specious in the management and conservation of Kolah Ghazi National Park is more significant. This is due to the relatively high level of richness of the wildlife species in the region, such as such as Gozella subgutturosa and Capra aegagrus are valuable assets of the region and need to be protected [12].

According to figure 5, other factors such as access routes, watering places, plant life and topography were used to classified protection areas.

One of the important conservation factor is existence of valuable species in any region. In this study the valuable species of Kolah Ghazi national park, was determined (like Aquila Chrysaetos), and the density and dispersion of which were observed and identified. Another important factor in the classification of the protection areas was the presence and density of these species [13-16]. Also, specious that have a low population density and also are vulnerable (such as Isfahan mouflon) are considered as another important basis for conservation classification in the region.

\section{RESULTS}

According to Figure 2 and according to the results obtained from the frequency of wildlife species in the four seasons, the highest frequency was related to the summer and the lowest was the winter.

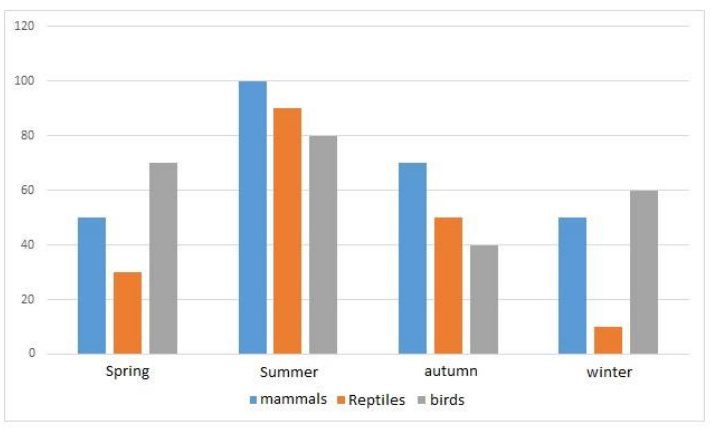

Figure 2: Comparison of wildlife abundance in different seasons

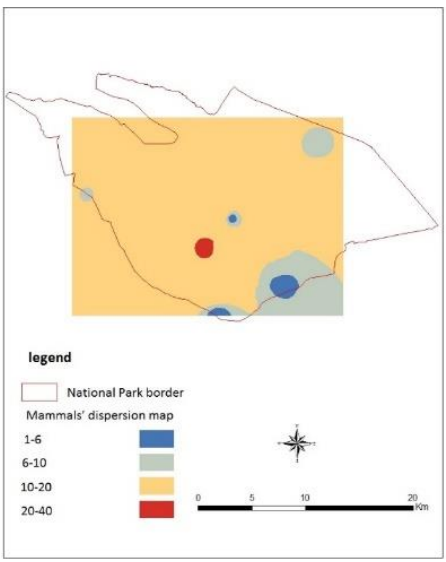

Figure4: Mammals desperations map

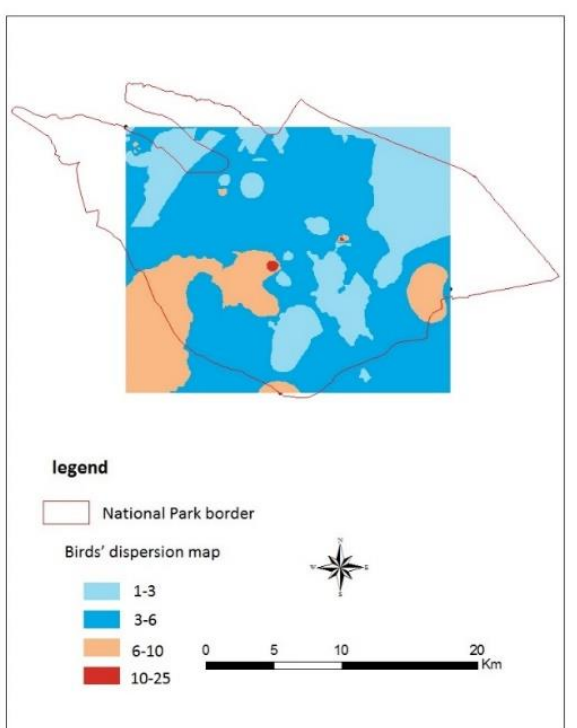

Figure 3: Birds desperation map

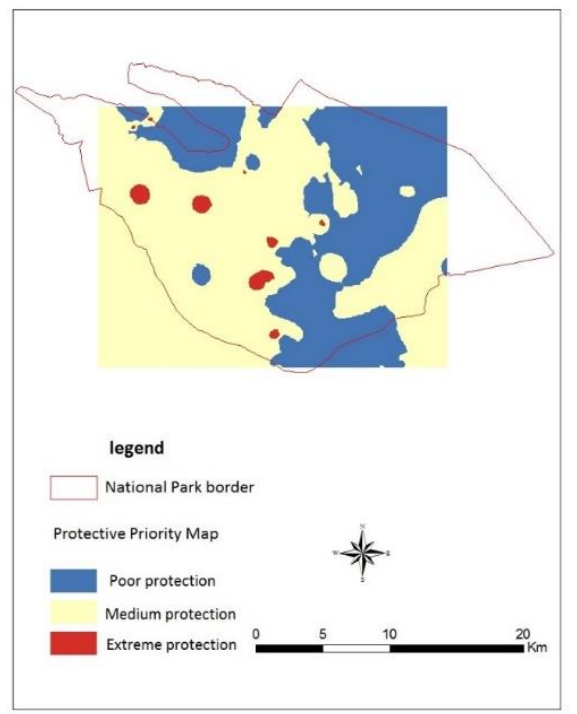

Figure 5: Protected Zoning Map, Kolah Ghazi National Park

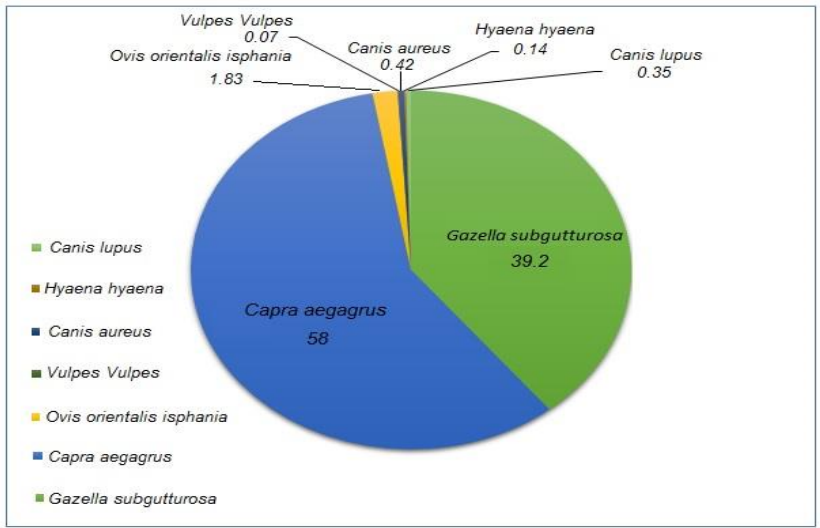

Figure 6: Mammals' abundance percent (Kolah Ghazi national park)

According to a census conducted by the Department of Environmental Protection Isfahan in 2016 the highest population is for Capra aegagrus and the smallest population is Vulpes. (Figure 6) 


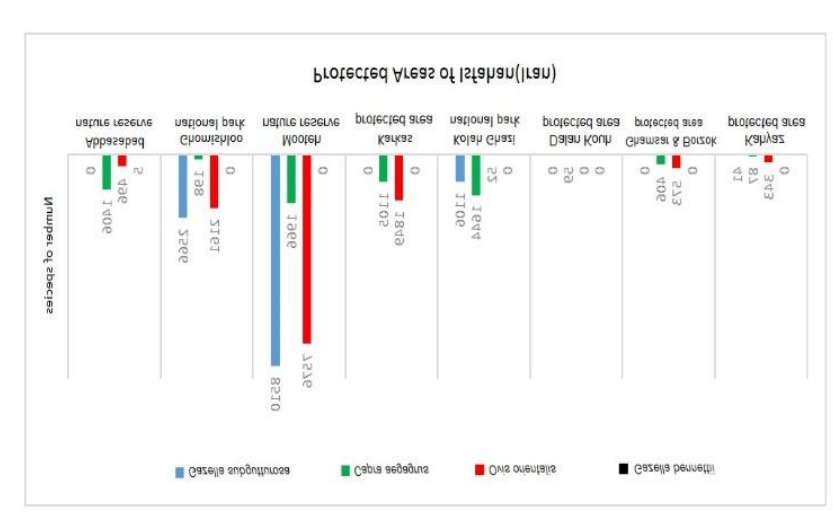

Figure 7: The number of artiodactyla animals in different regions of Isfahan, Iran

According to the census in 2016, the largest population of artiodactyl was related to Mooteh wildlife and the smallest population related to Daalaankooh protected area. According to figure 7, Kolah Ghazi National Park is in fourth place, and compared to the other areas has no favorable conditions in terms of populations, the number of animals in this region is not desirable, thus, proper measures need to be taken to protect the wildlife in the region.

\section{CONCLUSION}

Sensitive conservative areas have higher diversity and frequency than the other areas, there for, special conservative managements should be considered for these areas Conservation solutions for areas which are rich in their specious.

1- Installing telephoto cameras in order to estimate the diversity

2- Installing Closed circuit television to prevent hunting

3- Increasing observations

4- Increasing research and investigation

5- $\quad$ Advertisement and informing

6- Using smart tags

7- maintaining the key species in the ecosystem

8- successful management in ecosystem

9- Integrating management strategies

\section{REFERENCES}

[1] Morrison, Michael, L., Marcot, Bruce, G., Mannan, R., William. 1992. Wildlife habitat relationships: concepts and applications. Madison, WI: University of Wisconsin Press. 343 p.Moradpanah, Manijeh, Hajar, Moradpanah. 2017. Zoning of Maloosan protected area using GIS. Environmental Science and Technology, 19 (4) ,465-474.

[2] Latifi, Milad, Raadaan, Alireza, Ahmadi, Mozhgan, Moshtaghi, Mino. 2017. Investigating the evaluation of sustainable strategic management of ecotourism and ecosystem in Kolah Ghazi national mark, Isfahan. The first international conference.

[3] Sushinsky, J.R., Rhodes, J.R., Possingham, H.P., Gi Fuller, R.A. 2012 How should we grow cities minimize their biodiversity impacts. Global
Change Biology, 19, 401-410. (doi:10.1111/gcb.12055).

[4] Farrashi, Azita, Shariati, Mitra. 2013. Conservation zoning of Kolah ghazi national park with a multicriteria evaluation approach. Ecology scientific quarterly. 57

[5] Center, L.W. 1996. Environmental Impact Assessment Mc Graw Hil Book Co. Baltimore, 20, 45-56

[6] Nasab, A., Zahra, and Mahdi, S. 2015. Ranking the birds' habitat in Bakhtegan national park and wildlife reserve using habitat value index, in order to develop a management plan for the region.

[7] Bellocq, M.I., Leveau, L.M., and Filloy, J. 2016. Urbanization and bird communities: Spatial and temporal patterns emerging from southern South America. In: Murgui E, Hedblom M (eds) Ecology and conservation of birds in urban environments. Springer, Heidelberg, 35-54.

[8] Beninde, J., Veith, M., and Hochkirch, A. 2015. Biodiversity in cities needs space: a meta-analysis of factors determining intra-urban biodiversity variation. Ecology Letters, 18 (6), 581-592.

[9] Dallimer, M., Davies, Z.G., Diaz-Porras, D.F., Irvine, K.N., Maltby, L., Warren, P.H., Armsworth, P.R., Gaston, K.J. 2015. Historical influences on the current provision of multiple ecosystem services. Global Environmental Change, 31, 307-317.

[10] Dyson, Robert, G. 2004. Strategic Development and SWOT analysis at the university of warwick, European Journal of Operational Research, $152,631-640$

[11] Gutzwiller, K.J., and Barrow, W.C. 2003. Influences of roads and development on bird communities in protected Chihuahuan desert landscapes. Biological Conservation, 113, 25-237.

[12] Mack, E.L., Firbank, L.G., Bellary, P.E., Hinsley, S.A., and Veitch, N. 1997. The comparison of remotely sensed and ground-based habitat area data using species-area models. Journal of Applied Ecology, 34, 12221228

[13] Zade, N., Saeide, Yavari, Ahmadreza. 2005. Evaluation of the ecological capacity of the Khabar national park for zoning and planning using GIS software.

[14] Schneider, A., Friedl, M.A., and Potere, D. 2010 Mapping global urban areas using MODIS 500-m data:new methods and datasets. Remote Sensing of Environment, 114, 1733-1746. (doi: 10.1016/j.rse.2010.03.003)

[15] WCS. 1980. Guideline for comparing protected habitats together, In: Henrik Majnounian, 1379, Protected Area of Iran (principles \& Guideline for conservation and Management of protected Areas), Appendix 25, Department of Environment, Tehran: 440.

[16] Zafar, Maria S., Baig, Anwar, M., Irfan, Muhamm. 2011 ,2nd International Conference on Environmental Science and Technology , IPCBEE,

6 ,

V2-6-V2-9. 